\title{
Factors Influencing Allopurinol Initiation in Primary Care
}

Lorna E. Clarson, $P b D^{1}$

Samantha L. Hider, $P b D^{1,2}$

Jobn Belcher, $P b D^{1}$

Edward Roddy, $M D^{1,2}$

Christian D. Mallen, $P b D^{1}$

${ }^{1}$ Research Institute for Primary Care \& Health Sciences, Keele University, Keele, Staffordshire, United Kingdom

${ }^{2}$ Haywood Academic Rheumatology Centre, Staffordshire and Stoke-on-Trent, Partnership NHS Trust, Haywood Hospital, Burslem, Staffordshire, United Kingdom

\begin{abstract}
Despite guidance on appropriate initiation, urate-lowering therapy is prescribed for only a minority of patients with gout. Electronic health records for 8,142 patients with gout were used to investigate the effect of age, sex, comorbidities, number of consultations, and meeting internationally agreed eligibility criteria on time to allopurinol initiation. Time to first prescription was modeled using multilevel Cox proportional hazards regression. Allopurinol initiation was positively associated with meeting eligibility criteria at diagnosis of gout, but negatively associated with becoming eligible after diagnosis. Managing gout as a chronic disease, with regular reviews to discuss allopurinol treatment, may reduce barriers to treatment.
\end{abstract}

Ann Fam Med 2017;15:557-560. https://doi.org/10.1370/afm.2137.

\section{INTRODUCTION}

$\mathrm{D}$ espite recent reports that $44 \%$ of primary care patients with gout fulfil guideline indications for urate-lowering therapy at diagnosis, and that $87 \%$ become eligible within 5 years, only a minority of those eligible patients with gout commence treatment. ${ }^{1-3}$ This study investigated factors influencing initiation of allopurinol for treatment of gout in primary care.

\section{METHODS}

Primary care electronic health records (EHRs) from the Clinical Practice Research Datalink (CPRD) were analyzed for 8,386 patients with a diagnosis of gout. These patients were originally the gout cohort of a larger retrospective matched-cohort study investigating gout and risk of vascular disease. ${ }^{4}$ All patients having gout in that study were eligible for this analysis, but 244 patients were excluded because of missing prescription data, resulting in a study population of 8,142 gout patients. Patients were older than 50 years with an incident diagnosis of gout between 1987 and 1999 to allow 10 years of follow-up.

The outcome of interest was time to first prescription of allopurinol (the most commonly used urate-lowering therapy in the United Kingdom). Putative factors that might be associated with allopurinol prescribing and potential confounders were: age, sex, exposure to alcohol (categorized into ever exposed, never exposed, or missing), body mass index (normal $\leq 25$, overweight $>25$, or missing), burden of comorbidities (Charlson Comorbidity Index), ${ }_{1}^{5}$ total number of general practitioner consultations during follow-up for any reason (quartiles), number of gout-related consultations (continuous) and meeting criteria for urate-lowering therapy, derived from the European League Against Rheumatism and the American College of Rheumatology guidelines ) ( 2 or more gout attacks in 12 months, nephrolithiasis, chronic kidney disease, diuretic therapy or tophi) at diagnosis of gout or during follow-up. ${ }^{5,6}$

Time from the date of the first coded entry for gout (baseline) in the EHR to the date of issue of the first prescription for allopurinol was modeled using multilevel Cox proportional hazards regression. Patients not prescribed
Lorna Clarson

Research Institute for Primary Care \& Health Sciences, Keele University Keele, Staffordshire, ST5 5BG, UK 1.clarson@keele.ac.uk 
allopurinol were censored at the earliest of 10 years follow-up, transfer out, or death.

Putative factors of interest were identified from the EHR and entered into a full model. Shared frailty was used to account for clustering of prescribing behavior by practice allowing subject-specific interpretation of model coefficients. A significant likelihood ratio test statistic confirmed the variation in allopurinol initiation times among practices. The proportional hazards assumption was tested using generalized linear regression of the scaled Schoenfeld residuals on functions of time. Where a nonzero slope indicated a violation of the proportional hazards assumption, time-dependent covariates were generated by creating interactions of the predictors and a function of survival time. These time-varying covariates were included in the final model and time-varying effects were accommodated using the $\operatorname{tvc}()$ option in Stata 14 (StataCorp LP).

\section{RESULTS}

Sample characteristics are displayed in Table 1. Median follow-up time available for the cohort was 31 months (interquartile range [IQR] 8-64 months). Median time to first prescription of allopurinol was 8 months (IQR 0-41 months).

Those eligible for allopurinol at baseline were more likely to receive it (hazard ratio $[\mathrm{HR}]=1.41 ; 95 \% \mathrm{CI}, 1.29-1.54)$ than ineligible patients. Those who became eligible following their diagnosis of gout were less likely to receive an allopurinol prescription than those eligible at baseline (HR $=0.77$; 95\% CI, 0.69-0.85).

Factors associated with time to allopurinol prescription are shown in Table 2. The hazard ratios for the time-varying covariates reflect how the risk is changing per unit time. For example, for sex and chronic kidney disease (CKD) the risk increases by $0.07 \%$ and decreases by $1 \%$ respectively.

The time-varying covariates indicate a change in the strength of the association with each additional unit of time; for example, for every additional month of follow-up the hazard ratio for allopurinol initation in men increased by 0.007 (0.004-0.01).

\section{DISCUSSION}

Those meeting the internationally agreed-upon eligibility criteria for urate-lowering therapy, ${ }^{5,6}$ par-
Table 1. Sample Characteristics ( $N=8,142$ )

\begin{tabular}{|c|c|c|}
\hline & $\begin{array}{l}\text { Allopurinol } \\
\text { Prescribed } \\
n=3,283\end{array}$ & $\begin{array}{c}\text { Allopurinol } \\
\text { Not Prescribed } \\
n=4,859\end{array}$ \\
\hline Male, \%, (No.) & $70.9(2,327)$ & $67.9(3,300)$ \\
\hline Mean age at diagnosis of gout, $y^{a}$ & 65.4 (SD 10.2) & 66.9 (SD 11.1) \\
\hline \multicolumn{3}{|l|}{ Eligible for allopurinol, \%, (n) } \\
\hline At baseline & $34.7(1,139)$ & $27.1(1,320)$ \\
\hline Ever & $25.4(835)$ & $34.7(1,684)$ \\
\hline \multicolumn{3}{|l|}{$\begin{array}{l}\text { Criteria by which eligible for } \\
\text { allopurinol, \%, (No.) }\end{array}$} \\
\hline Not eligible & $39.4(1,294)$ & $37.7(1,832)$ \\
\hline CKD & $2.8(92)$ & $4.1(197)$ \\
\hline Diuretic therapy & $40.7(1,336)$ & $47.5(2,310)$ \\
\hline$\geq 2$ gout attacks in 12 months & $14.2(466)$ & $7.8(381)$ \\
\hline Tophi & $1.3(41)$ & $0.9(43)$ \\
\hline Urolithiasis & $1.6(54)$ & $2.0(96)$ \\
\hline \multicolumn{3}{|l|}{ Exposure to alcohol, \%, (No.) ${ }^{c}$} \\
\hline Never exposed to alcohol & $11.9(392)$ & $13.2(641)$ \\
\hline Exposed to alcohol & $76.3(2,506)$ & $71.6(3,479)$ \\
\hline Not recorded & $11.7(385)$ & $15.2(739)$ \\
\hline \multicolumn{3}{|l|}{ BMI, \%, (n) } \\
\hline $\mathrm{BMI} \leq 25 \mathrm{~kg} / \mathrm{m}^{\mathrm{b}}$ & $19.1(626)$ & $24.1(1,173)$ \\
\hline $\mathrm{BMI}>25 \mathrm{~kg} / \mathrm{m}^{\mathrm{b}}$ & $64.9(2,129)$ & $56.1(2,724)$ \\
\hline Not recorded & $16.1(528)$ & $19.8(962)$ \\
\hline $\begin{array}{l}\text { Charlson comorbidity score at } \\
\text { gout diagnosis, mean }\end{array}$ & 1.7 (SD 1.9) & $0.8(1.2)$ \\
\hline $\begin{array}{l}\text { Consultation for gout during } \\
\text { follow-up, median No. (IQR) }\end{array}$ & $2(1-11)$ & $1(1-10)$ \\
\hline $\begin{array}{l}\text { Consultation for any reason during } \\
\text { follow-up, median No. (IQR) }\end{array}$ & $42(4-279)$ & $88(8-440)$ \\
\hline \multicolumn{3}{|c|}{$\begin{array}{l}\mathrm{ACR}=\text { American College of Rheumatology; } \mathrm{BMI}=\text { body mass index; } \mathrm{CKD}=\text { chronic kidney } \\
\text { disease; EULAR = European League Against Rheumatism; } \mathrm{IQR}=\text { interquartile range; } \mathrm{SD}=\text { stan } \\
\text { dard deviation. }\end{array}$} \\
\hline \multicolumn{3}{|l|}{ a Cohort older than 50 years. } \\
\hline \multicolumn{3}{|c|}{${ }^{\mathrm{b}}$ Eligibility according to the EULAR and ACR guidelines. ${ }^{5,6}$} \\
\hline \multicolumn{3}{|c|}{$\begin{array}{l}\text { "Exposure to alcohol measured as ever exposed/never exposed or not recorded closest to the } \\
\text { date of diagnosis of gout. }\end{array}$} \\
\hline
\end{tabular}

ticularly at diagnosis, were more likely to receive allopurinol, suggesting that it is not lack of awareness of guidelines which underlies suboptimal prescribing, as has been reported elsewhere. ${ }^{1,7}$ The short median time to first prescription of allopurinol, a positive association with eligibility at diagnosis, and the negative association with becoming eligible after diagnosis suggest decisions to initiate allopurinol are made early. When considered alongside the positive association between allopurinol initiation and recurrent consultations for gout, an eligibility criterion that by definition can only be met after diagnosis, it may be that clinicians are more likely to offer, or patients may be more likely to accept allopurinol after multiple acute attacks. Such was not the case for recurrent consultations for any reason which was negatively associated with allopurinol initiation, further suggesting that the presence of other eligibility criteria is not 
reviewed as part of ongoing care, particularly in the presence of other comorbidities.

Evidence suggests that general practitioners perceive gout management to be acute rather than preven-

Table 2. Adjusted Hazard of Receiving an Allopurinol Prescription

\begin{tabular}{|c|c|c|}
\hline & Hazard Ratio & $95 \% \mathrm{Cl}$ \\
\hline \multicolumn{3}{|l|}{ Eligible for allopurinol (ever) } \\
\hline Not eligible & 1 [referent] & 1 [referent] \\
\hline CKD & 3.48 & $2.31-5.26$ \\
\hline Diuretic therapy & 2.49 & $2.10-2.94$ \\
\hline $\begin{array}{l}\geq 2 \text { Consultations for gout in } \\
12 \text { months }\end{array}$ & 3.88 & $3.22-4.68$ \\
\hline Tophi & 2.10 & $1.10-4.00$ \\
\hline Urolithiasis & 2.33 & $1.44-3.78$ \\
\hline Age at diagnosis of gout ${ }^{\mathrm{a}}$ & 1.00 & 0.99-1.01 \\
\hline Male & 0.59 & $0.51-0.69$ \\
\hline \multicolumn{3}{|l|}{ Overweight (BMI >25kg/mb) } \\
\hline Not overweight $\left(\mathrm{BMI} \leq 25 \mathrm{~kg} / \mathrm{m}^{\mathrm{b}}\right.$ ) & 1 [reference] & 1 [reference] \\
\hline Overweight & 1.14 & $1.02-1.27$ \\
\hline Not recorded & 0.88 & $0.74-1.04$ \\
\hline \multicolumn{3}{|l|}{ Exposure to alcohol } \\
\hline Never exposed & 1 [reference] & 1 [reference] \\
\hline Ever exposed to alcohol & 1.07 & $0.93-1.24$ \\
\hline Not recorded & 0.80 & $0.65-0.99$ \\
\hline Charlson comorbidity score $\mathrm{a}^{\mathrm{a}}$ & 0.84 & $0.81-0.88$ \\
\hline $\begin{array}{l}\text { Number of consultations for gout }{ }^{\mathrm{a}} \\
\text { (during entire follow-up) }\end{array}$ & 1.05 & $1.02-1.08$ \\
\hline \multicolumn{3}{|l|}{$\begin{array}{l}\text { Number of consultations for any } \\
\text { reason (during entire follow-up) }\end{array}$} \\
\hline Quartile $1(0-34)$ & 1 [reference] & 1 [reference] \\
\hline Quartile 2 (34-64) & 0.44 & $0.37-0.61$ \\
\hline Quartile 3 (65-119) & 0.20 & $0.16-0.24$ \\
\hline Quartile $4(\geq 120)$ & 0.07 & $0.05-0.09$ \\
\hline \multicolumn{3}{|l|}{ Time-varying covariatesc } \\
\hline Male & 1.007 & $1.004-1.011$ \\
\hline $\begin{array}{l}\text { Number of consultations for gout }{ }^{\mathrm{a}} \\
\text { (during entire follow-up) }\end{array}$ & 1.002 & $1.001-1.002$ \\
\hline \multicolumn{3}{|l|}{$\begin{array}{l}\text { Number of consultations for any } \\
\text { reason (during entire follow-up) }\end{array}$} \\
\hline Quartile $1(0-34)$ & 1 [reference] & 1 [reference] \\
\hline Quartile 2 (34-64) & 1.005 & $1.001-1.009$ \\
\hline Quartile 3 (65-119) & 1.009 & $1.005-1.037$ \\
\hline Quartile $4(\geq 120)$ & 1.015 & $1.012-1.020$ \\
\hline \multicolumn{3}{|l|}{ Eligible for allopurinol (ever) } \\
\hline Not eligible & 1 [referent] & 1 [referent] \\
\hline CKD & 0.990 & $0.982-0.999$ \\
\hline Diuretic therapy & 0.991 & 0.988-0.994 \\
\hline $\begin{array}{l}\geq 2 \text { consultations for gout in } \\
12 \mathrm{mo}\end{array}$ & 0.985 & $0.980-0.989$ \\
\hline Tophi & 0.994 & $0.979-1.008$ \\
\hline Urolithiasis & 0.990 & $0.982-0.999$ \\
\hline \multicolumn{3}{|c|}{$\begin{array}{l}\mathrm{ACR}=\text { American College of Rheumatology; } \mathrm{BMI}=\text { body mass index } ; \mathrm{CKD}=\text { chronic kidne } \\
\text { disease; EULAR = European League Against Rheumatism. }\end{array}$} \\
\hline \multicolumn{3}{|c|}{ Note: Model is adjusted for all listed variables and clustering by practice. } \\
\hline \multicolumn{3}{|l|}{$\begin{array}{l}\text { a Denotes a continuous variable. } \\
\text { bEligibility according to the FULAR and }\end{array}$} \\
\hline
\end{tabular}

tive $^{8}$ and assumes that patients would prefer treatment for an acute attack rather than long-term prophylactic medication. ${ }^{7}$ For reasons that remain unclear, men are thought to be reluctant to consider long-term uratelowering therapy ${ }^{9}$ and were less likely to be prescribed allopurinol in this study, although conflicting results have been reported elsewhere. ${ }^{1}$ There is also evidence that patient preferences may change, ${ }^{10}$ suggesting a more structured chronic disease management for gout to revisit these preferences may remove some barriers to allopurinol treatment.

Study limitations included the inability to account for patient and clinician preferences in allopurinol-prescribing decisions, serum uric acid levels, and reliance on physician coding to identify gout cases, risking potential misclassification.

Our findings suggest that more frequent chronic disease reviews to revisit patient preferences and eligibility for allopurinol may reduce barriers to successful treatment of gout. Further research should focus on understanding patient and prescriber preferences in allopurinol prescribing and why patients who become eligible for allopurinol after diagnosis do not receive it.

To read or post commentaries in response to this article, see it online at http://www.AnnFamMed.orgl content/15/6/557.

Key words: gout; allopurinol; primary care

Submitted July 27, 2016; submitted, revised, February 23, 2017; accepted April 28, 2017.

Funding support: Funding was from the National Institute of Health Research School for Primary Care Research (NIHR SP(R). LEC is supported by a National Institute for Health Research Academic Clinical Lectureship. CDM is funded by a UK National Institute for Health Research (NIHR) Research Professorship (NIHR-RP-2014-04-026), the NIHR Collaborations for Leadership in Applied Health Research and Care West Midlands, and the NIHR School for Primary Care Research.

\section{References}

1. Kuo CF, Grainge MJ, Mallen C, Zhang W, Doherty M. Eligibility for and prescription of urate-lowering treatment in patients with incident gout in England. JAMA. 2014; 312(24):2684-2686.

2. Roddy E, Zhang W, Doherty M. Concordance of the management of chronic gout in a UK primary-care population with the EULAR gout recommendations. Ann Rheum Dis. 2007;66(10):1311-1315.

3. Jeyaruban A, Larkins S, Soden M. Management of gout in general practice-a systematic review. Clin Rheumatol. 2015;34(1):9-16. 
4. Clarson LE, Hider SL, Belcher J, Heneghan C, Roddy E, Mallen CD. Increased risk of vascular disease associated with gout: a retrospective, matched cohort study in the UK clinical practice research datalink. Ann Rheum Dis. 2015;74(4):642-647.

5. Zhang W, Doherty M, Bardin T, et al.; EULAR Standing Committee for International Clinical Studies Including Therapeutics. EULAR evidence based recommendations for gout. Part II: Management. Report of a task force of the EULAR Standing Committee for International Clinical Studies Including Therapeutics (ESCISIT). Ann Rheum Dis. 2006;65(10):1312-1324.

6. Khanna D, Fitzgerald JD, Khanna PP, et al.; American College of Rheumatology. 2012 American College of Rheumatology guidelines for management of gout. Part 1: systematic nonpharmacologic and pharmacologic therapeutic approaches to hyperuricemia. Arthritis Care Res (Hoboken). 2012;64(10):1431-1446.
7. Spencer K, Carr A, Doherty M. Patient and provider barriers to effective management of gout in general practice: a qualitative study. Ann Rheum Dis. 2012;71(9):1490-1495.

8. Humphrey C, Hulme R, Dalbeth N, Gow P, Arroll B, Lindsay K. A qualitative study to explore health professionals' experience of treating gout: understanding perceived barriers to effective gout management. J Prim Health Care. 2016;8(2):149-156.

9. Singh JA, Shah N, Edwards NL. A cross-sectional internet-based patient survey of the management strategies for gout. BMC Complement Altern Med. 2016;16(1):90.

10. Richardson JC, Liddle J, Mallen CD, et al. A joint effort over a period of time: factors affecting use of urate-lowering therapy for long-term treatment of gout. BMC Musculoskelet Disord. 2016;17(1): 249. 